\title{
A Study on Developmental Direction of Interface Design for Gesture Recognition Technology
}

\author{
Dong Min Lee ${ }^{1}$, Jeong Ju Lee ${ }^{2}$ \\ ${ }^{1}$ Department of Industrial Design, Kyung Hee University, Yongin, 446-701 \\ ${ }^{2}$ Smart Solution Lab, FEIT, Seoul, 137-267
}

\begin{abstract}
Objective: Research on the transformation of interaction between mobile machines and users through analysis on current gesture interface technology development trend. Background: For smooth interaction between machines and users, interface technology has evolved from "command line" to "mouse", and now "touch" and "gesture recognition" have been researched and being used. In the future, the technology is destined to evolve into "multi-modal", the fusion of the visual and auditory senses and "3D multi-modal", where three dimensional virtual world and brain waves are being used. Method: Within the development of computer interface, which follows the evolution of mobile machines, actively researching gesture interface and related technologies' trend and development will be studied comprehensively. Through investigation based on gesture based information gathering techniques, they will be separated in four categories: sensor, touch, visual, and multi-modal gesture interfaces. Each category will be researched through technology trend and existing actual examples. Through this methods, the transformation of mobile machine and human interaction will be studied. Conclusion: Gesture based interface technology realizes intelligent communication skill on interaction relation ship between existing static machines and users. Thus, this technology is important element technology that will transform the interaction between a man and a machine more dynamic. Application: The result of this study may help to develop gesture interface design currently in use.
\end{abstract}

Keywords: Interaction design, Gesture interface, Multi-modal, Sensor technology

\section{Introduction}

급격한 기술의 발달에 의한 사회 변화는 인간 중심의 디 자인을 지향하는 UX 디자이너에게 새로운 도전일 수도 있 다. UX 디자이너들은 기술과 사용 환경 변화와 발전에 따 른 새로운 조건에 적합한 디자인과 서비스를 제공하고자 노 력하고 있다. 사용자는 운전 중이거나 그냥 길을 걸어가는 중일 수도 있으며 또 전혀 다른 예상치 못한 행동을 취할 수 있는 것 같이 다양한 사용자의 사용형태와 needs가 있음을 이해해야 한다. 이제는 더 이상 키보드나 커다란 스크린 그
리고 마우스를 이용하는 것만으로는 사용 환경의 특성과 사 용자의 만족을 채워주기에 불충분한 현실이다.

특히 스마트폰의 확산으로 모바일 장치에 있어 인터페이 스 기술의 중요성은 더욱 늘어나고 있다. 아무리 좋은 기능 을 지닌 제품이라 할지라도 사용하기 불편하면 사용자는 그 제품을 외면하기 때문이다. 그래서 과학기술자들은 1940년 대 처음 컴퓨터를 처음 개발하면서부터 이에 대한 연구를 꾸준히 진행하여 왔다. 컴퓨터를 기반으로 하는 많은 기술 이 발전함에 따라 사람들은 좀 더 자유롭고 편리한 $\mathrm{HCI}$ (Human Computer Interaction)를 요구하게 되었으며, 이 를 동기로 컴퓨터 인터페이스의 기술이 변화되고 있다.

Corresponding Author: Dong Min Lee. Department of Industrial Design, Kyung Hee University, Yongin, $446-701$.

Mobile: +82-10-9072-1677, E-mail: mick@khu.ac.kr

Copyright@2012 by Ergonomics Society of Korea(pISSN:1229-1684 eISSN:2093-8462). All right reserved.

(c) This is an open-access article distributed under the terms of the Creative Commons Attribution Non-Commercial License(http://creativecommons.org/licenses/by-nc/3.0/), which permits unrestricted non-commercial use, distribution, and reproduction in any medium, provided the original work is properly cited. http://www.esk.or.kr 


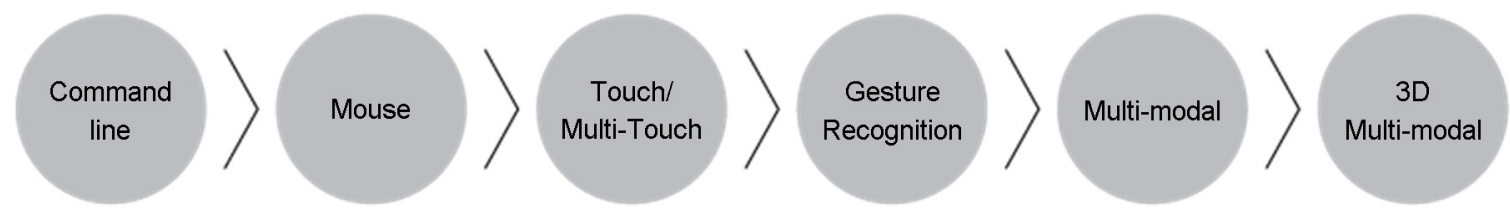

Figure 1. Changes in the development of computer interfaces

대개 SF 영화 속에서 우리의 미래를 예상해 볼 수 있는데 '스타트랙'에서는 사람의 음성이나 동작은 물론 대상이 다른 행성인 이라고 해도 컴퓨터가 이해하고 번역해서 필요한 정 보를 금방 눈앞에 표시해 주는 인터페이스가 등장하고, 'AI' 에서는 인간의 감정까지 이해하거나 표현할 수 있는 휴먼 인터페이스가 실현되는 것을 볼 때, 우리가 꿈꾸는 이상적인 인터페이스의 미래상이 너무 먼 애기는 아닌 현재진행형인 것을 알 수 있다.

현재 사용자의 편의성을 극대화한 이상적인 인터페이스를 만들기 위한 노력들로서 음성인식이나 화상인식 기술에 대 한 연구가 진행되어 왔으며, 이미 상당부분이 가능해지고 있 다. 아직은 자연스럽게 커뮤니케이션을 할 수 있는 수준에 이르기 까지는 시간이 더 필요하지만 지속적인 연구와 기기 의 성능 발전에 따라 인터페이스 기술과 디자인은 점점 진화 하고 있다.

Figure 1은 컴퓨터 인터페이스 기술 변화의 개략을 보여 준다. 커맨드 라인 방식의 인터페이스는 우리가 가장 오랫동 안 써오던 인터페이스이다. 이후 펀치카드나 종이테이프 등 의 배치 방식과 함께 컴퓨터를 제어하는데 사용되었고, 텔레 타이프형 기계들이 사용되면서 사용자로 하여금 해당 프로 세스의 일부분에 해당하는 명령어를 변화시키고, 거의 실시 간으로 컴퓨터로부터 피드백을 받을 수 있어서 널리 사용되 었다. 이후 등장한 마우스는 사용자와 컴퓨터 간의 인터랙션 을 훨씬 다양하고 손쉽게 할 수 있도록 하였다. 지금은 마우 스가 없다면 데스크톱 컴퓨터로는 작업을 하지 못할 정도로 마우스는 보편화되고 표준화된 인터페이스이다. 40년 전, 스 탠퍼드 연구소의 연구진 더글러스가 개발한 마우스는 현대 컴퓨터 개발과정 가운데 핵심적인 부품으로 사용되었고, 현 재까지 인터페이스의 중심으로 사용되어 왔다. 다양한 어플 리케이션을 사용자가 마우스를 통해서 인트렉션을 할 수 있 어 물리적 인터페이스로서 마우스 자체의 하드웨어 디자인 과 함께 화면의 디자인이 함께 발전하였다.

세 번째 등장한 인터페이스는 터치 인터페이스를 들 수 있다. 애플사의 아이패드를 통해 폭발적으로 성장한 터치패 드는 기존 노트북 컴퓨터를 중심의 대중적인 포터블 컴퓨터 시장에서 사용자가 정보의 생산자가 아닌 소비자로서의 혁 신적 편의성을 강조한 인터페이스로 시장을 장악해 나가고 있다. 마우스를 이용하는 노트북과 달리 터치패드는 화면에
사용자가 직접적으로 터치하는 동작에서 사용자의 손가락 움직임을 전자판이 추적하여 작동되도록 제작되었다. 이 터 치패드의 기술을 스크린에 적용한 것이 터치스크린이다. 터 치스크린은 은행의 ATM에서 보편화되기 시작하였고, 마우 스 사용이 어려운 고정형 공공 기기에 많이 쓰였다. 터치스 크린 기술은 스마트폰과 스마트패드에 접목되어 일반적인 터치 및 멀티터치를 이용한 제스처 인식 기술로 급속히 발전 하고 있다. 여러 스마트 기기 제조사들이 멀티터치스크린 방 식의 기기들을 개발하고 있고, 마이크로소프트는 새로운 OS Windows7에 멀티터치 인식 플랫폼을 제공함으로써 모든 분야에서 다양한 응용이 예상되고 있으며 다른 매개체 없이 사용자의 직접적 터치를 통해 인터랙션을 가진다는 부분에 서 사용자의 직관이나 편의성 극대화와 관련하여 디자인이 방향이 전개되고 있다.

최근에는 센서에 직접적인 접촉을 통해 신호를 가하는 인 터페이스와 달리 카메라를 통한 시각정보, 가속도 센서, 자 이로 센서, 지자계 센서를 결합한 비접촉 모션정보의 입력 을 이용하여 사용자의 제스처를 인식하는 인터페이스가 개 발되고 있다. 닌텐도 위 (wii) 와 아이폰은 사용자들의 동작을 이해하여 게임이나 해당 애플리케이션을 동작시킬 수 있다.

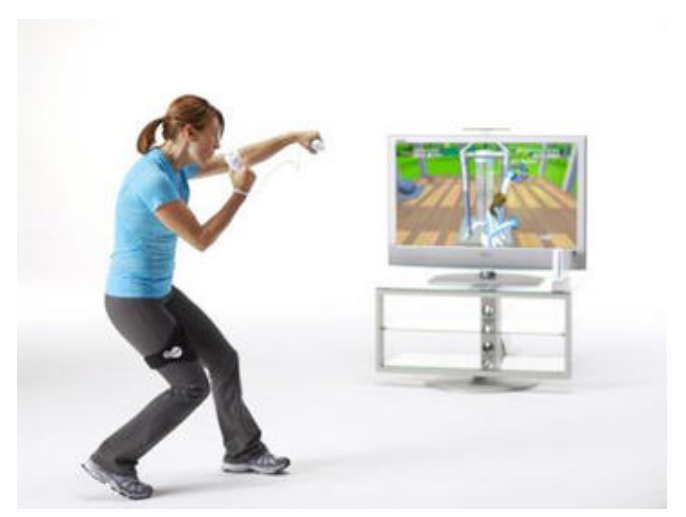

Figure 2. Wii-fit picture related driving

이러한 비접촉 센서의 발달로 인하여 사용자의 손이나 몸 의 움직임, 표정 등을 실시간으로 정확히 인식하여 기기에 정보를 전달함으로써 이전에 인터페이스에 비해 더욱 쉽게 
기기와 인터랙션이 가능하게 되었다. 여기서 더 나아가 전문 가들은 인간이 대화에서 사용하는 각종 지적정보 전달 기능, 즉 오감을 종합적으로 활용할 수 있을 때 가장 이상적인 인 터페이스 기술이 구현될 것으로 예상하고 있다. 이런 이유로 최첨단 기술의 하나인 시청각 신호를 융합하여 사용하는 멀 티모달(multi-modal) 인터페이스 기술이 제안되고 있다. 멀티모달이란 인간이 타인과의 대화에 있어서 상대방의 말 을 귀로 들으면서 표정으로부터 다른 정보를 동시에 얻는 것처럼 인간과 기계 사이에서 음성, 키보드, 펜, 제스처 등의 다양한 수단을 이용하여 인터랙션을 하는 방법을 말한다. 그 리고 머지않아 3 차원 가상 세계와 오감 및 뇌파를 전부 활 용할 수 있는 $3 \mathrm{D}$ 멀티모달 인터페이스 기술로 발전해 갈 것으로 예측되고 있다.

이러한 인터페이스의 변화 속에서 제스처 관련 기술은 중 요하게 대두되고 있다. 제스처란 특별한 정보를 상대에게 전 달하거나 강조하기 위해 언어 대신 또는 언어와 동시에 사용 하는 신체(손, 머리, 몸, 표정 등)의 움직임으로 정의될 수 있다. 연구에 의하면 실제 커뮤니케이션에 언어에 의한 정보 전달은 $7 \%$, 제스처나 비언어적 수단에 의한 정보 전달은 $35 \%$, 얼굴 표정에 의한 정보 전달은 $55 \%$ 라고 알려져 있다. 그만큼 제스처를 포함한 시각정보는 지능형 사용자 인터페 이스를 구현함에 있어서 없어서는 안 될 중요한 요소이다.

본 논문에서는 점점 진화하고 있는 인터페이스 기술 분야 중 제스처 인터페이스와 관련하여 기술의 발전 및 동향을 알아보고 제스처 인터페이스의 활용으로 인한 기기와 인간 간의 인터랙션 변화에 따른 디자인방향에 대해 기술한다.

\section{The Gesture Recognition Technology and the Current Application State}

제스처 인터페이스 기술은 제스처를 기반으로 하여 정보 를 얻을 수 있는 방법에 따라 센서 기반 제스처 인터페이스, 터치 기반 제스처 인터페이스, 영상 기반 제스처 인터페이스 의 총 3 가지로 분류한다. 센서 기반 제스처 인터페이스는 사 용자의 신체 및 기기 몸체에 센서를 부착해서 인식하는 기술 이고, 터치 기반 제스처 인터페이스는 신체 일부를 디스플레 이 패널이나 기기에 접속 또는 터치하여 인식하는 기술이다. 영상 기반 제스처 인터페이스는 영상처리 및 컴퓨터 비전 기 술을 이용하여 사용자의 움직임 정보를 인식하는 기술로, 머 리, 손, 신체, 표정 등을 제스처로 구분한다.

\subsection{Sensor-based gesture recognition}

인간의 제스처는 3 차원 공간에서 이루어지기 때문에 그 움직임을 수치적으로 정량화하는 일은 매우 어렵다. 그러나 최근 컴퓨터를 이용한 제조 기술의 눈부신 발전과 함께 상응 하는 센서 기술도 그 발전 속도로 여러 방법이 나오고 있다. 현재 센서 기반의 제스처 인식을 위해서는 가속도 센서가 널 리 사용되고 있고, 최근에는 GPS와 지자계 센서 정보를 결 합한 인식 기술들도 개발되고 있다.

가속도센서는 출력 신호를 처리하여 물체의 가속도, 진동, 충격에 의한 힘의 변화를 측정하는 것으로 물체의 운동 상태 를 상세하게 감지할 수 있다. 가속도 센서 기술은 기존에는 운송수단과 공장자동화 및 로봇 등의 제어 시스템에 사용되 었지만, 최근에는 애플의 아이폰과 같은 모바일 장치나 닌 텐도 위(wii) 및 소니의 무브와 같이 게임기용 컨트롤러 등에 도 널리 활용되고 있다. 위(wii)와 무브같은 경우 체감형 게 임의 대표적인 예로 마니아층은 물론 캐주얼 이용자들까지 만족시키고 있다.

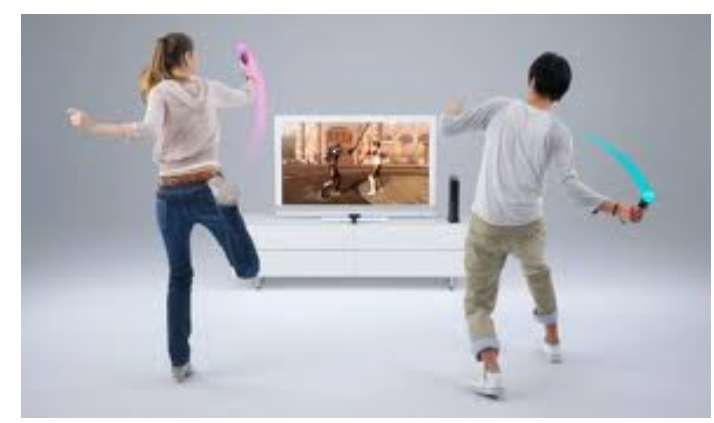

Figure 3. Sony-playstation move

기존 센서 기반 제스처 인식 기술은 몸의 관절부위나 글러 브에 다축 가속도 및 자이로 센서를 장착하여 3차원 움직임 정보로 몸 및 손의 제스처를 인식하였지만, 최근에는 모바일 기기의 보급으로 인해 센서들이 기기에 장착되었고, 내부의 센서 정보를 활용하여 고도의 상호작용이 가능하게 되었다. 이 기술의 대표적인 예 중의 하나가 이미 오래 전에 상용화 된 삼성의 동작인식이 가능한 비트박스폰으로 알려진 애니 콜 SCH-310을 들 수 있다. 이 모바일폰은 가속도 센서의 3 차원 정보를 직접적으로 이용하여 궤적 추정 없이도 제스 처 인식이 가능하다. 이 기술을 이용해서 흔드는 제스처만으 로도 게임을 즐기거나 악기를 연주할 수 있다. 이 기술은 사 용자가 모바일폰을 이용하여 3 차원 공간의 제스처를 수행하 거나 흔들 때 가속도 센서는 모션의 가속도를 측정하게 된다. 측정된 가속도 신호는 제스처를 인식한 후, 최종적으로 모바 
일폰의 어플리케이션을 통하여 수행된 결과를 사용자에게 보여주어 경험할 수 있게 해준다.
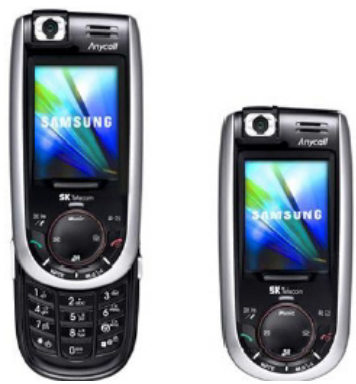

Figure 4. Samsung-Anycall SCH-310

예를 들면 아이폰용 레이싱 게임의 경우 가속도 센서뿐만 아니라 자이로 센서를 이용해 한쪽으로 기울이면서 방향을 틀 수 있다. 조작 시 이러한 피드백을 결과를 통해서 사용자 들은 더 실제와 같은 스피드감과 몰입을 느낄 수 있다.

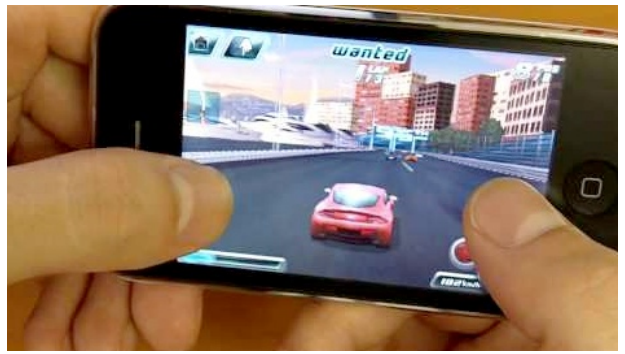

Figure 5. Apple-Iphone

사용자 입장에서는 기기에 내장된 센서를 통한 동작으로 인해 인터랙션의 피드백을 인지 못할 수 있는데 이를 위해 다양한 연구가 필요한 실정이다.

\subsection{Touch-based gesture recognition}

터치를 인식하는 방식 중 주로 사용되고 있는 것이 저항막 방식과 정전용량인데 최근에 소형 모바일 기기에 있어서 터 치스크린은 가장 중요한 인터페이스 장치이다. 특히 기기 전 면을 스크린으로 사용하는 스마트폰에 있어서는 터치 인터 페이스를 어떻게 만드느냐에 사용자의 선호도가 달라진다.

소형 모바일 기기의 특성상 기기의 전면이 스크린되어 사 용하기 때문에 기계식 버튼들은 가상의 버튼 오브젝트로 표 현되는 경우가 많다. 기계적이고 물리적인 스위치 기능을 소 프트웨어적으로 처리함에 따라 기존의 단순터치 기능 인터
페이스와는 전혀 다른 개념의 인터페이스 기술들이 등장할 수 있게 되었다. 특히 접촉 방식의 터치동작에 의해 프로세 스를 기동하거나 제어하는 것 보다 여러 단계의 명령어들을 하나의 제스처로 표현하는 비접촉식 방법은 획기적인 기술 과 사용편의성으로 인해서 많은 주목을 받고 있다. 다양한 센서에 의해 기기 스스로 인지하여 작동하는 부분에서는 사 용자에게 명확한 시각, 청각, 촉각 등의 피드백에 대한 것과 터치와 제스처의 연계로 나타나는 다양한 인터랙션은 보다 사용자 편의의 직관적 표현을 중심으로 연구되고 있다.

정전식 터치 방식은 아이팟 터치에서 처음 사용되었는데 정전식 터치가 더 많은 터치 방식을 제공하기 때문이지만 좀더 부드러운 터치감을 경험할 수 있기 때문이기도 하다. 이는 안드로이드폰이 터치인식을 기존의 웹에서의 클릭을 기반으로 한 명령으로 인식한 것에 비해 아이폰은 터치의 시작 움직임 끝의 간단한 명령으로 인식했기 때문이다. 이러 한 물리적, 소프트웨어적인 기술의 결합으로 아이팟 터치는 예전에 없던 경험을 사용자에게 주어 높은 선호도를 가지게 되었다.

모바일 기기 및 특정 기기로만 국한된 터치 기반 제스처 는 새로운 운영체제인 Window7의 등장으로 테스크톱에 이용할 수 있게 되어 넓은 터치 사용 환경이 도입될 예정 이다. Window7의 응용 프로그램에서 멀티터치 UX(User experience)를 적용하는 방법을 'Good step', 'Better step', 'Best step'의 3단계로 나누어 설명하고 있다.

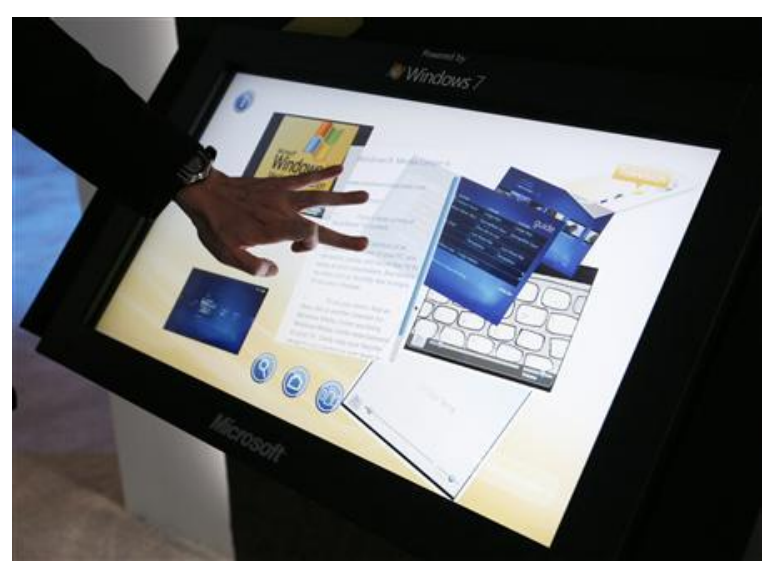

Figure 6. Multi-touch in window7

'Good step'는 Window7에서 기본적으로 제공해주는 터 치 UX로 스크롤바의 스크롤 기능, 메모장의 가상키보드 호 출 기능, 윈도우 탐색기나 인터넷 익스플로어와 같은 프로그 램의 네비게이션 기능들이 여기에 포함된다. 이 기능들은 아 이폰에서 기본적으로 제공되는 기능과 비슷하게 손가락 터 
치를 통한 화면의 스크롤바 이동 및 메모장에 가상의 키보 드를 불러와서 텍스트 입력 작업을 하거나. 윈도우 탐색기의 파일 리스트 영역에서 손가락을 좌/우로 움직이면 탐색기의 탐색경로를 변경하는 기능이다. 이런 기능들을 활용하는 것 이 터치 UX의 'Good step' 단계이다.

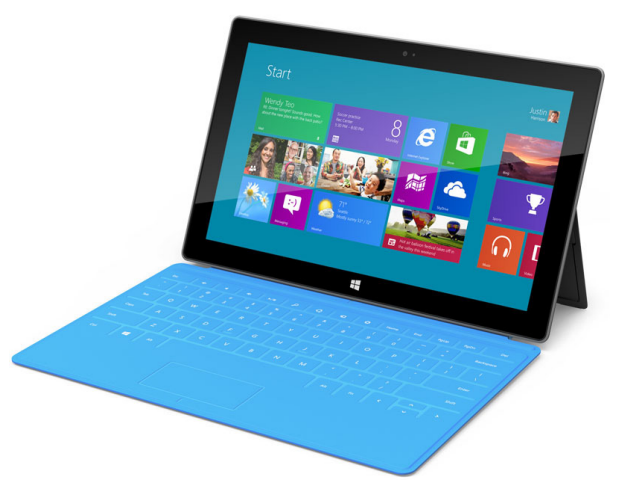

Figure 7. Microsoft surface

'Better step'은 제스처를 이용하는 방법이다. Windows7 은 기본적으로 터치 입력이 들어오면 $\mathrm{MSDN}$ 에서 정의한 9 가지 제스처에 해당 하는지 여부를 판단하여 해당 제스처 가 있을 경우에는 제스처 메시지(WM_GESTURE)를 응용 프로그램으로 전달한다. 해당 메시지에는 제스처 인식에 필 요한 터치의 시작 좌표와 끝 좌표, 제스처의 상태 등의 정보 들이 응용 프로그램에 제공된다.

마지막으로 3번째 단계인 'Best step'에서는 가장 상세한 터치 UX를 구현하는 방법을 제공한다. 이 단계에서는 제스 처 메시지(WM_GESTURE) 처럼 OS에서 자체적으로 가공 된 좌표 값, 수치 값들과는 다르게 아무 처리도 되지 않은 원시 터치 데이터들이 터치 메시지(WM_TOUCH)를 통해 전달되며, 이를 이용해 저 레벨 수준의 구현이 가능하게 된 다. 터치 메시지(WM_TOUCH)의 구조체는 특정 터치 입력 을 다른 입력과 구별하는 터치ID가 할당되어 여러 개의 터 치점을 인식할 수 있어 멀티터치 제스처를 수행할 수 있다.

사용편의성 극대와 기술의 발달을 통하여 터치 기반 제스 처 인식 기술은 앞으로 급격한 발전이 예상되며 모든 입출력 장치는 터치를 기본 환경으로 구축될 것이다. 또한 터치를 이용한 각종 서비스와 콘텐츠가 개발됨으로써 이 기술의 가 치는 상승할 것으로 예상되며 제스처를 이용한 다양한 응용 방법에 대한 연구가 이루어 질 것이다.

\subsection{Video-based gesture recognition}

센서를 몸이나 손에 직접 부착하거나 여러 종류의 센서를
기기 내부에 장착해야 하는 센서 기반의 제스처 인식 방법에 비해 제품에 장착된 카메라를 이용하면 제품의 가격을 줄일 수 있는 이점을 가지고 있다. 최근에 들어 모바일 기기에 기 본적으로 장착된 카메라를 이용하여 머리, 몸, 손(손가락)의 움직임 정보를 이용하여 직접 터치를 하지 않고 제스처를 인 식하는 특허들이 많이 출원되고 있다. 최근 $\mathrm{SKY}$ 에서 출원 한 VEGA LTE는 휴대폰 카메라에 모션 UI를 탑재하여 화 면을 손가락으로 직접 터치하지 않고 화면 위에서 손으로 넘기는 제스처만으로 전화를 받을 수 있는 기술을 선보였다. 이 기능을 이용하여 VEGA LTE에서는 전화 수신뿐만 아니 라 사진, 책, 음악을 넘기는 기능으로 활용하고 있다. 그러나 휴대폰과 같은 이동 단말기의 경우 사용 환경이 급격히 변화 에 따라 조명도 심하게 변해 현재 널리 사용되고 있는 휴대 폰용 카메라를 이용할 경우 조명의 변화에 따른 컬러의 변 화 때문에 인식률이 낮아져서 이를 보완할 기술 개발이 절 실하며 화면에서 기능에 대한 명확한 설명과 동작의 피드백 에 대한 디자인은 미흡하다.

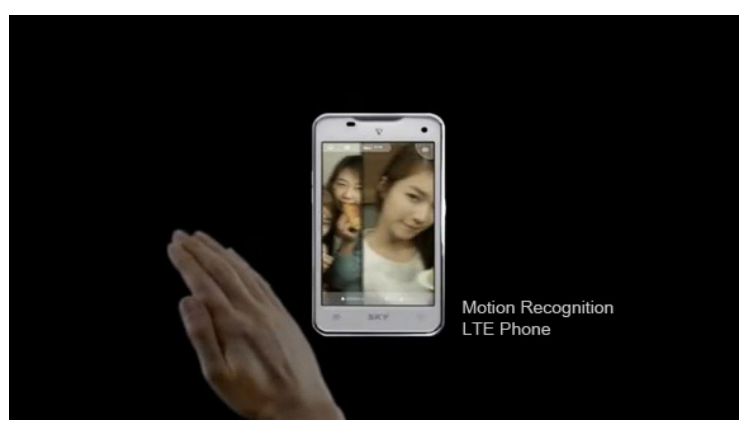

Figure 8. SKY-Vega LTE Motion recognition

기술적 대안으로 기존 하나의 카메라를 이용하는 방법에 서 스테레오 카메라를 이용하는 방법도 제안되고 있다. 이 방식은 좌우에 설치된 스테레오 카메라에서 영상 값을 추출 하고, 추출된 좌, 우 영상에서 대응되는 정합점을 찾아낸다. 찾아낸 정합점 영상의 차이(disparity)를 이용하여 3차원 깊 이 정보를 추출할 수 있다. 기존의 스킨 컬러 인식법의 문제 점인 유사한 컬러값 분할을 3 차원 깊이 정보에 따라 더 정 확히 원하는 영역을 분리해 낼 수 있는데 이를 화면 안에서 공간감과 위치와 동작에 대한 피드백을 사용자의 편의성을 고려한 인터페이스 디자인의 개발이 필요하다.

스테레오 카메라를 이용한 인터랙티브 애니메이션은 소리, 그림자, 빛, 색상 등 다양한 오감 요소를 통해 인터랙티브한 반응을 실제로 느낄 수 있다. 3 차원공간의 무대 벽면에 애니 메이션이 재생되며 관객이 무대에 등장하는 위치에 따라 애 니메이션 캐릭터들이 등장한다. 무대 위쪽에 호스트 컴퓨터 
카메라가 있고 관객들의 각종 명령 동작의 영상에 따라서 애니메이션의 재생 속도, 움직이는 가속도, 운동방향, 진폭 등의 수치들이 관객의 움직임에 따라 반응한다. 3 차원의 공 간의 무대의 3측벽면의 위쪽에 부속 카메라가 있고, 주로 각 캐릭터 애니메이션의 관객의 입장할 때 간단한 대화나 인 사 감지 시스템이다.

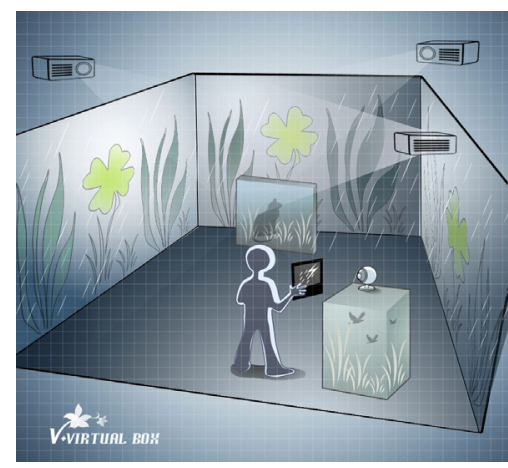

Figure 9. Virtual garden

영상 기반 제스처 인식 기술은 영상처리 부분에서 많은 계산량을 필요로 하므로, 현재 사용되고 있는 모바일 기기에 적용하기 어렵지만 최근 들어 스마트폰을 중심으로 첨단 프 로세서를 장착하여 실시간 영상처리가 기능하게 되었다. 특 히 컴퓨터비전 기술을 결합한 증강현실 기반 각종 어플리케 이션은 이 분야의 가능성을 충분히 보여주고 있으며 다양하 고 새로운 인터페이스 디자인을 나타내면서 새로운 가능성 을 보여주고 있다.

\section{Conclusion}

본 논문에서는 최근 주목 받고 있는 지능형 인터페이스인 제스처 인터페이스 기술에 대해 센서 기반, 터치 기반, 영상 기반 제스처 인터페이스를 구분하여 발전 방향 및 기술의 응 용 사례에 대해서 설명하였다. 특히 인터페이스 디자인의 관 점에서 기술적으로 대표적인 내용과 그 중요한 동향을 분석 하였다.

비접촉 제스처 기반 인터페이스 기술은 기존의 정적인 인 터페이스 기술을 동적인 개념으로 확장시킨 것으로, 인간이 지니고 있는 지능형 대화 기능을 기계에 실현하기 위한 가장 중요한 요소 기술의 하나로 최근 널리 인식되고 있다. 이 제 스처 인터페이스 기술은 앞으로 정보기기의 활용도와 사용 편의성을 높이는데 큰 역할을 할 것이며, 최근의 제품의 부
가가치가 사용자 중심의 인터페이스의 만족도에 의해 결정 되고 있다는 것을 인식할 때 이 분야 연구의 중요성은 매우 크다고 볼 수 있다. 이 기술의 적용 분야는 차세대 휴대폰, 차세대 $\mathrm{PC}$, 로봇, 디지털 홈 네트워크 등의 다양한 분야에서 핵심 공통 기술로 작용할 것이다. 최근 IT 제품과 인텔리전 트 서비스의 경쟁력과 차별화의 가장 중요한 요소로 부각되 고 있다. 이에 대응한 기술 개발과 사용성 연구가 시급히 요 구되고 있기에 새롭고 다양한 사용 환경과 사용자 요구에 맞 는 능동적 제스처 인터페이스 디자인 연구가 보다 활성화되 기를 기원한다.

\section{References}

Archibugi, D., "Patenting as an Indicator of Technological Innovation: A Review", Science and Public Policy, Vol. 19, No. 6, 1992.

Cheung, G. K., Baker, S., Hodgins, J. and Kandade. T., "Markerless Human Motion Transfer", International Symposium on 3D Data processing. Visualization and Transmission, pp. 373-378, 2004.

Choi, E.-S., Bang, W.-C., Cho, S.-J., Yang, J., Kim, D.-Y. and Kim. S.-R., "Beatbox Music Phone: Gesture-based Interactive Mobile Phone using a Tri-axis Accelerometer", in IEEE International Conference on Industrial Technology(ICIT 2005), pp. 97-102, 2005.

Fano, A. and Gershman, A., "Issues and challenges in ubiquitous computing: The future of business services in the age of ubiquitous computing", Communications of the ACM. Special Issue: Issues and challenges in ubiquitous computing, Vol. 45, No. 2, pp. 83-87, 2002.

Furness, T. A. and Kocian, D. F., "Putting Humans into Virtual Space", Proceedings of the 16th Conference on Aerospace Simulation, 2(pp. 48-52), San Diego. CA. 1986.

Hannukela, J., Huttunen, S., Sangi, P. and Heikkila. J., "Motion-based finger tracking for user interaction with mobile devices", European Congerence on Visual Media Production, pp. 1-6, 2007.

Lee, M., Yoong Choon Chang and TseKian Neo., "S Fast motion Sensing Algorithm for Vision Based Mobile Phones User Interface Design", IEEE Pacific Rim Conference on Communications Computers and Signal Procissing, pp. 336-341, 2009.

Kallio, S., Kela, J. and Mantyjarvi. J., "Online gesture recognition system for mobile interaction", IEEE International Conference on Systems. Man and Cybernetics, Vol. 3, pp. 2070-2076, 2003.

Paperno, E., Sasada, I. and Leonovich. E., "A New Method for magnetic Position and Orientation Tracking", IEEE Transaction on Magnetics, Vol. 37, No. 4, pp. 1938-1940, 2001

Potamanos, G., Graf, H. P. and Cosatto. E., "An Image Transform Approach For HMM Based Automatic Lipreading", International Congerence on Image Processing, pp. 173-177, 1998.

Rabiner, L. R., "A tutorial on hidden markov models and selected 
applications in speech recognition", Proceedings of the IEEE, Vol. 77, No. 5, pp. 257-286, 1989.

Rajeev Sharma, Vladimir I Pavlovic and Thomas S. Huang., "Toward Multimodal Humman-Computer Interface", Proceedings of the IEEE, Vol. 86, No. 5, pp. 853-869, 1998.

S. Burak Gokturk, Hakan Yalcin and Cyrus Bamji., "A Time - Of - Flight Depth Sensor - System Description, Issues and Solutions", International Congerence on Computer Vision and Pattern Recognition Workshop, Vol. 3, pp. 35-44, 2004.

Steve Hotelling, Joshua A Strickon and Brian Q Huppi., "Multipoint touchscreen", US, 2006-0097991(7663607), 2006.

Wei Du and Hua Li., "Vision based gesture recognition system with single camera", International Conference on Signal Processing, Vol. 2, pp. 1351-1357, 2000.

Yun Xiaoping, Bachmann, E. R. and McGhee, R. B., "A Simplified Quaternion-Based Algorithm for Orientation Estimation From Earth Gravity and Magnetic Field Measurements", IEEE Transactions on Instrumentation and Measurement, Vol. 57, No. 3, pp. 638-650, 2008.

\section{Author listings}

Dong Min Lee: mick@khu.ac.kr

Highest degree: MFA, 3-D Design, Cranbrook Academy of Art

Position title: Professor, Department of Industrial Design, Kyung Hee University

Areas of interest: UCD, UI, UX, HCI

Jeong Ju Lee: jay@feit.co.kr

Highest degree: BID, Department of Industrial Design, Kyung Hee University

Position title: Designer, Smart Solution Lab, FEIT Creative Solution Group Areas of interest: User Experience, Product Design

Date Received : 2012-07-23

Date Revised :2012-07-31

Date Accepted : 2012-07-31 